\title{
AS OBRAS DO ACERVO DO MACC NOS SALÕES DE ARTE CONITEPORÂNEA DE CAMPINAS: 1960 e 70.
}

\author{
Renata Cristina de Oliveira Maia Zago \\ renatazago@iar.unicamp.br
}

\section{Resumo}

Esta pesquisa consistiu em discutir a importância dos Salões de Arte Contemporânea de Campinas nos anos 1960 e 1970, momento introdutor das "vanguardas" na cidade de Campinas. Devido à escassez de material para desenvolver a pesquisa encontramos duas alternativas para resgatar informações: buscar depoimentos de artistas que participaram dos Salões de Arte Contemporânea de Campinas, além de antigos diretores do Museu de Arte Contemporânea de Campinas (MACC); e levantar e analisar artigos de jornais de época, visando retraçar a importância desses Salões no contexto da arte contemporânea brasileira. O trabalho seguinte foi analisar as vinte obras selecionadas, pertencentes ao acervo do MACC.

Unindo então essas duas etapas, pudemos analisar de forma consistente a relação entre o panorama histórico-cultural local e nacional da época, inserindo as obras dos artistas selecionados, pertencentes ao acervo do MACC, nesse contexto e em suas respectivas produções, além de retraçar o papel dos Salões de Arte Contemporânea de Campinas.

Porém, neste texto, será dada ênfase à realização sistemática dos Salões de Arte Contemporânea de Campinas, discutindo seus desdobramentos e seu caráter inovador.

\section{Introdução}

No final dos anos de 1940, e nos anos 1950 a arte brasileira de "vanguarda", em especial as correntes abstratas, tiveram grande força e importância nas metrópoles brasileiras. Nos anos que antecederam imediatamente a década de 1950 foram fundados três importantes museus: em 1947 o Museu de Arte de São Paulo (MASP), em 1948 o Museu de Arte Moderna (MAM) de São Paulo e o MAM do Rio de Janeiro. Além da criação desses museus começaram a acontecer, em 1951, os Salões Nacionais de Arte Moderna no Rio de Janeiro, e em 1952, em São Paulo, o Salão Paulista de Arte Moderna. Além disso, em 1951, aconteceu a I Bienal Internacional de São Paulo e, por conseguinte, sua realização sistemática.

Entretanto, se os anos 1950 foram marcados pela difusão da arte abstrata no país - e destacamos aqui a criação dos grupos Ruptura, formado em 
1952, em São Paulo e Frente, formado em 1954, no Rio de Janeiro, que deram origem aos movimentos concreto e neoconcreto, respectivamente - nos anos 1960 a arte brasileira de vanguarda foi assinalada por um profundo experimentalismo. "Assistiu-se então no país à derrocada progressiva da abstração, à retomada da figuração em um novo registro, de caráter alusivo, e às primeiras tentativas de integração entre arte e cultura de massa". ${ }^{1}$

E foi em meio a esse contexto que o MAC-USP foi criado, em 1963, com propósitos diferentes dos Museus de Arte Moderna de São Paulo e Rio de Janeiro, já que sua proposta era formar um acervo com obras da mais "nova" arte contemporânea. Assim, no ano de sua fundação, Walter Zanini, seu primeiro diretor, instituiu um evento denominado "Exposição do Jovem Desenho Nacional" que permitia a inscrição de três trabalhos por artista de até 35 anos de idade. Entretanto, a própria dinâmica do evento, a interação entre o diretor do Museu, os artistas e sua produção, levou à gradativa inclusão de trabalhos de pintura, escultura e objetos, criando-se assim, em 1967, o programa Jovem Arte Contemporânea, que consistia na apresentação anual da produção de jovens artistas contemporâneos emergentes dedicados à pesquisa plástica atual. Um júri de seleção elegia inicialmente os trabalhos a serem apresentados na mostra, escolhendo, em seguida, aqueles que seriam adquiridos através de premiação. Desta forma, o museu manteve a sua coleção atualizada com a criação jovem e contemporânea.

Ademais, nos anos 1970 a interdisciplinaridade se firma através da apresentação de objetos, instalações, conferências e mesas de debates. Internacionalmente, bem como no Brasil, a arte se desenvolveu em direção à valorização do processo, da idéia, dos multimeios. São utilizados os mais variados meios e técnicas. Cristina Freire afirma que

“a tão debatida efemeridade das propostas lança a noção de arte como processo decorrente de uma idéia, de um objeto impalpável para o centro do debate. O esforço do artista, nesse período, vai no sentido de dar corpo ao invisível, tornar material uma idéia que não teria, necessariamente, apelos formais." ${ }^{2}$

E as obras apresentadas nas JACs dos anos 1970 tinham esse caráter. O MAC-USP tornou-se, sobretudo, identificado pelo estilo irreverente, agressivo e, muitas vezes, aberto a todas as experiências. De acordo com Zanini não se sabia quase sempre no que resultariam as mostras e os eventos da "geração 70", com tanta repressão em volta.

\footnotetext{
${ }^{1}$ Maria de Fátima Morethy Couto, Por uma vanguarda nacional. A crítica Brasileira em busca de uma identidade artística (1940-1960), Campinas, Editora da Unicamp, 2004, p.200.

${ }^{2}$ Cristina Freire, Poéticas do Processo - Arte conceitual no Museu, São Paulo, Iluminuras, 1999, p.30.
} 


\section{A situação das artes plásticas em Campinas}

Durante os anos 1940 e 50 na cidade de Campinas ainda eram realizados os Aslões de Belas Artes, com supremacia absoluta da arte acadêmica. Segundo recente entrevista com Bernardo Caro, além desses tradicionais Salões de Belas Artes, realizados anualmente, os "grandes mestres" sempre expunham no asguão do Teatro Municipal, e as obras que ganhavam o primeiro prêmio nos Salões eram adquiridas pela Prefeitura $\mathrm{Municipal}^{3}$. Essa situação fez com que a Secretaria de Educação e Cultura tivesse a idéia de criar uma Pinacoteca, utilizando os prêmios aquisições para iniciar seu acervo. A criação da mesma, porém, nunca se concretizou.

Mas a "explosão" dos recentes acontecimentos artísticos nos grandes centros, anteriormente mencionados, foi aos poucos chegando às cidades do interior e provocando mudanças na maneira dos jovens artistas entenderem a arte de seu tempo, o que os levou a uma ruptura tardia com o "academicismo". Isso deu origem então, em setembro de 1957, à I Exposição de Arte Contemporânea de Campinas, no saguão do Teatro Municipal. Assim, o espaço anteriormente reservado apenas para a arte tradicional começou a ceder lugar à arte nova. Um ano após tal exposição alguns artistas reuniram-se e formaram o Grupo Vanguarda ${ }^{4}$.

O objetivo do grupo era uma união de artistas para realizarem exposições, diferente, por exemplo, dos grupos Ruptura e Frente, em que os artistas seguiam uma linha ou um pensamento em comum, dentro do grupo. Nada havia em comum nas obras dos artistas do Vanguarda, apenas uma vontade de mostrar a Campinas uma nova maneira de expressão, uma nova tendência. Segundo o depoimento de dois dos artistas que participaram do grupo, Francisco Biojone ${ }^{5}$ e Bernardo Caro $^{6}$, estes tinham consciência de que não havia nada de vanguarda em sua arte, a não ser uma novidade para a cidade de Campinas. Confirmando então a informação, Thomaz Perina ${ }^{7}$ afirmou em recente entrevista que o Grupo Vanguarda, em especial Geraldo de Souza e Raul Porto, tinha grande ligação com os artistas concretos de São Paulo e que o grupo costumava freqüentar diversas exposições, demonstrando que se encontravam a par dos acontecimentos artísticos nacionais.

\footnotetext{
${ }^{3}$ Entrevista realizada pela autora com o artista em 24/06/2004.

4 O "Grupo Vanguarda" era formado pelos artistas Bernardo Caro, Edoardo Belgrado, Enéas Dedeca, Francisco Biojone, Franco Sacchi, Geraldo de Souza, Geraldo Jurguensen, Maria Helena Motta Paes, Mário Bueno, Raul Porto e Thomaz Perina.

${ }^{5}$ Em entrevista realizada pela autora em 18/05/2004.

${ }^{6}$ Em entrevista realizada pela autora em 24/06/2004.

${ }^{7}$ Em entrevista realizada pela autora em 22/09/2004.
} 
Essa vontade dos artistas campineiros de mostrar sua arte tornou-se uma necessidade e um problema quando o Teatro Municipal da cidade foi féchado por período indeterminado. A galeria de arte Aremar, pertencente a Raul Porto era o único local em que o grupo ainda podia expor. Dessa forma, criar um local para exposições permanentes de arte contemporânea tornou-se o maior objetivo do grupo.

Observar o que ocorria no panorama artístico de São Paulo, como os acontecimentos periódicos das Bienais, a fundação do Museu de Arte Contemporânea da USP, além de uma exposição organizada e trazida por Walter Zanini do MAC-USP a Campinas, realizada no saguão do Teatro Municipal no mesmo ano de 1963, foram fatores decisivos para que a Secretária da Educação e Cultura, na época Da. Jacy Milani, apoiasse a idéia defendida pelo grupo Vanguarda: a criação de um museu.

Assim, ocorreu o I Salão de Arte Contemporânea de Campinas e a concomitante fundação do Museu de Arte Contemporânea de Campinas (MACC) na Avenida da Saudade junto à Secretaria Municipal de Cultura. Somente após alguns anos, em 1976, o MACC recebeu um prédio que seria sua sede definitiva, onde se encontra atualmente, na Avenida Benjamin Constant, 1633.

A realização deste I Salão de Arte Contemporânea de Campinas e dos conseguintes teve como objetivo iniciar o acervo do museu recém fundado. Ademais, a situação política em que o Brasil encontrava-se impulsionou a realização desses Salões e de outras grandes mostras fora dos grandes centros, como as Bienais da Bahia e os Salões de Arte Moderna de Brasília. Após o golpe de 1964 e a instauração da ditadura militar iniciou-se uma grande repressão que se tornou ainda mais acirrada nos grandes centros após a decretação do AI-5 (Ato Institucional $\mathrm{n}^{\circ}$ 5). Isso proporcionou a abertura do eixo cultural brasileiro. Segundo Zanini, São Paulo voltou a ser a capital brasileira da arte apenas no final dos anos $1970 .^{8}$

\section{Os Salões de Arte Contemporânea de Campinas}

Os Salões de Arte Contemporânea de Campinas (SACCs) aconteceram de 1965 a 1977, inicialmente realizadas nos mesmos moldes de um salão tradicional foram, ao longo de suas realizações, modificando seu caráter e sua estrutura e chegaram a destacar-se em âmbito nacional, principalmente nos anos de 1974 e 75 .

${ }^{8}$ Apud Cristina Freire, Poéticas do Processo - Arte conceitual no Museu, São Paulo, Iluminuras, 1999, p.25. 
Assim, resolvemos aqui dar ênfase às mostras de 1965, visto que esta inaugurou a tradição do evento, à de 1969 na qual começaram as transformações, e àquelas realizadas nos anos de 1974 e 75.

\section{Salão de Arte Contemporânea de Campinas}

A realização do I SACC foi de 1 a 30 de agosto de 1965. E, com a contribuição da Prefeitura e de algumas empresas privadas, foram outorgados vários prêmios e distribuídos na forma de prêmios aquisições em todas as categorias, além de menções honrosas aos artistas.

Este Salão reuniu as seções de Pintura, Escultura, Arquitetura, Arte decorativa e Arte gráfica e acharam-se inscritos 340 artistas, representantes de 26 cidades do país. Do júri de seleção e premiação das categorias Pintura, Escultura, Arte Gráfica e Arte Decorativa participaram Izar do Amaral Berlinck, Norberto Nicola e Mario Schenberg.

Neste I SACC, de caráter experimental, foram aceitas obras de quase duzentos artistas. Analisando a premiação - com base em pesquisas em catálogos, no livro tombo do MACC e na documentação encontrada e organizada constatamos que algumas destas obras foram adquiridas pelo museu ou por colecionadores particulares e outras foram apenas agraciadas com prêmios em dinheiro dados aos artistas pelos patrocinadores. Além disso, podemos destacar que alguns prêmios atribuídos possuem também um caráter honorífico (medalhas de ouro, prata e bronze).

Ademais, constatamos que, salvo algumas exceções como Lothar Charoux, Evandro Carlos Jardim e alguns integrantes do grupo Vanguarda, já reconhecidos na cidade de Campinas, a grande maioria dos artistas premiados estava no início de sua carreira durante esta época.

Em reportagem publicada pelo jornal de Campinas Correio Popular de 29 de agosto de 1965 há uma descrição superficial das obras selecionadas: "as mais modernas manifestações da pop-art, da ingenuidade dos primitivistas, do agonizante desespero dos surrealistas, passando ainda pelo concretismo, abstracionismo, realismo fantástico, tachismo (...)" ${ }^{\text {" }}$. Ainda no mesmo jornal, em depoimento, Geraldo Jurgensen afirma ter tomado conhecimento da importância do I SACC em Washington, pois na embaixada brasileira havia fotos e informações sobre a exposição.

Já na categoria Arquitetura em que participaram do júri Paulo Mendes da Rocha, Joaquim Guedes e Pedro Paulo Saraiva, segundo documento encontrado (em três vias) no arquivo do MACC nenhum dos projetos apresentou condições mínimas exigidas pelos jurados para participar do I SACC.

${ }_{9}^{9}$ Correio Popular, 29 de agosto de 1965, p. 19. 


\section{Salão de Arte Contemporânea de Campinas}

O V SACC foi realizado de 04 a 31 de outubro de 1969. Agora o Salão não se encontra mais dividido em categorias e não há mais a distribuição de prêmios honoríficos, além das obras premiadas terem diminuído consideravelmente e todas serem adquiridas pelo MACC.

Os componentes do júri deste Salão foram José Geraldo Vieira, Aracy Amaral, Waldemar Cordeiro, Walmir Ayala e Mário Barata. Este SACC recebeu inscrições de 271 artistas com 813 obras das quais o júri selecionou 261 obras de 87 artistas e outorgou prêmios aos seguintes artistas: Bernardo Caro, Cláudio Tozzi, Georgete Melhem,Gilberto Salvador, Geraldo Jurgensen, Henrique Leo Fuhro, Hudla Pintchovski, Inácio Rodrigues, Lucia Fleury de Oliveira, Mário Luiz Paulucci, Maria Helena Motta Paes, Maria Luiza Fávero, Pedro Moacyr Campos, Raul Porto, Ruth Bessoudo Courvoisier, Thomaz Ianelli, Thereza Miranda, Zama e Wanda Pimentel.

Os membros do júri prestaram depoimentos ao jornal de Campinas Correio Popular acerca das questões abordadas neste Salão afirmando que

"Embora mantendo o nome de Salão, mas já em curso de transformação para melhor, esta mostra de arte contemporânea justifica-se inicialmente por demonstrar o apreço que Campinas dedica à cultura e às artes, como expressão de nível de civilização.

A cidade é jovem e tradicional ao mesmo tempo e não seria justo que não se desse oportunidade para os interessados - estudantes, estudiosos, professores, diletantes populares vissem um resumo da criação estética contemporânea no país e interpretassem as suas afirmações e indagações. Sendo nacional, o Salão também estimula o desenvolvimento das artes visuais no país. A existência do Salão é importantíssima para a cidade, pois demonstra o alto grau de cultura e civilização que Campinas faz jus. É importante ressaltar que a mostra não é apenas expositiva, mas também possui um elevado caráter didático". ${ }^{10}$

\section{Salão de Arte Contemporânea de Campinas: Desenho Brasileiro 74}

O IX SACC aconteceu em Campinas de 26 de outubro a 24 de novembro de 1974. Esta mostra foi exposta no MAM - Rio de Janeiro em janeiro de 1975 e em março do mesmo ano em Brasília, na Sala de Exposições do Setor de Difusão Cultural.

O IX SACC foi de grande importância para o panorama artístico brasileiro, sendo divulgado e criticado nos maiores e mais relevantes meios de comunicação do país.

Segundo Roberto Pontual, que integrou a comissão organizadora da mostra, o SACC foi reajustado em seus propósitos e regulamentos, através da proposta de uma comissão formada por ele, Márcio Sampaio e Olívio Tavares

${ }^{10}$ Correio Popular, Campinas, 19 de outubro de 1969. 
de Araújo ${ }^{11}$. Podemos averiguar tal proposta descrita pelos críticos, encontrada e transcrita por mim dos arquivos de documentação do MACC:

"O ponto de partida para os reajustes propostos no IX SACC foi a verificação da inegável crise de representatividade e interesse que cerca, há algum tempo, as iniciativas desse tipo. Grande parte dos artistas brasileiros têm se recusado ao confronto, por motivos tão sutis quanto diversos, que vão desde a oposição ao suporte institucionalizado até, em certos casos, o medo de correr o risco de eliminação num cotejo competitivo, com desvantagem para a sua imagem no mercado. Em outros casos, a evolução e a incorporação de novas linguagens expressivas denunciariam com clareza a limitação da divisão em categorias nos salões, e a inadequação do tipo de espaço disponível. Havia a nossa frente duas opções. Uma, a abertura radical, que suprimisse o lado competitivo do certame, enfatizasse as pesquisas de vanguarda e transformasse o IV Salão numa promoção experimental. Outra, a opção documental, não no sentido nostálgico de uma arte vivida e acabada, mas sim no de apreender e demonstrar a vitalidade de um setor ora emergente na arte brasileira. Isso significava, também, a tentativa de recondução à mostra de alguns nomes mais ou menos ausentes, cuja obra faz parte dessa vitalidade e deve ser vista amplamente. A segunda opção pareceu-nos melhor, em função do caráter necessariamente informativo e didático de que se deve revestir um salão nas condições específicas de Campinas.

No momento em que optamos pelo caráter documental, tornou-se também coerente restringir o âmbito do levantamento, para que ele possa ser mais claro e eficaz. O desenho despontou como a linguagem mais e melhor usada nos último três ou quatro anos no Brasil, servindo inclusive como suporte para uma criação bastante não - convencional. Para exemplifica-la objetivamente, elaborou-se uma lista - base de vinte e um artistas convidados, que participarão do salão ao lado dos artistas regularmente inscritos e selecionados. Mantivemos o princípio de inscrição, seleção e premiação, pela evidência de um aspecto ainda positivo nesse esquema, qual seja a possibilidade de surgimento de novos nomes e propostas, que uma comissão normalmente não poderia conhecer. Por coerência e funcionalidade, também esse levantamento via - seleção ficou restrito à técnica do desenho, de forma a obter, inclusive, um panorama geral mais homogêneo.

Ressaltamos, finalmente que a proposta por nós apresentada para o IX Salão de Campinas pretende responder apenas ao momento específico, parecendo-nos a mais exeqüível neste instante. A abertura implícita na disposição do Conselho do Museu será evidentemente continuada na medida em que, nos próximos salões, novos projetos sejam apresentados por outras comissões, em função dos dados que então estiverem a seu dispor."

Assim, os críticos de arte tiveram plena liberdade para executar o IX Salão de Campinas, em seus mínimos detalhes, criando uma categoria de convidados para assegurar a representatividade do conjunto e que, ao mesmo tempo, manteve a seleção e premiação. Demonstrando grande rigor, os jurados aceitaram apenas 56 dos 266 trabalhos inscritos. Os artistas premiados foram os seguintes: Amador de Carvalho Perez, Bia Wouk, Cristina Tati, Eduardo Cruz, Eduardo Hotz, Eva Furnari, Geraldo Porto e Chico Franze, João Pirahy, Luis Guimarães (Guima), Luis Carlos Lindenberg, Marcos Concilio, Mauro Kleiman, Noni Geiger, Normando José Martinez Santos, Paulo de Tarso Viana de Souza, Rogerio Luz, Sergio Andrade, Terezinha Veloso, Vitor Gerhard e Yukio Suzuki.

No mesmo ano de 1974, no Museu de Arte Moderna de São Paulo houve o sexto Panorama, também privilegiando as artes gráficas: o desenho e a gravura. Porém, esta mostra passou por algumas modificações nos últimos

${ }^{11}$ Folha de São Paulo, 27 de outubro de 1974. 
anos, como a opção por não ter uma comissão julgadora, mas sim fazer convites a artistas já consagrados na época. Mas ainda assim eram distribuídos prêmios, a fim de aumentar a competitividade.

A meu ver, as duas mostras aproximam-se, inclusive pelo fato de apresentarem os mesmos artistas fundamentais. Olívio Tavares de Araújo, membro do júri, publicou na revista $V$ eja, "Não se pode negar que a versão campineira é mais concentrada e mais moderna". ${ }^{12}$ A própria lista de convidados (Anna Maria Maiolino, Arlindo Daibert Amaral, Barrio (Arthur Alípio Barrio Lopes), Carlos Alberto Fajardo, Carlos Eduardo Zimmermann, Carlos Vergara, Cildo Meireles, Luis Gregório Correia, Luis Paulo Baravelli, Luiz Alphonsus Guimarães, Madu (Maria do Carmo V. Martins), Manuel Augusto Serpa de Andrade, Marcos Coelho Benjamin, Maria do Carmo Secco, Mira Schendell, Roberto Magalhães, Tomoshige Kusuno, Tuneu (Antonio Carlos Rodrigues), Waltércio Caldas Júnior e Wilma Martins) procurou enfatizar uma certa linha que, se não era a vanguarda, pelo menos toca no que, naquele momento havia de mais bem informado.

Além disso, deve-se ainda destacar o caráter de abertura permanente que a realização deste Salão pretendia instaurar. "O que fizemos foi apenas uma proposta para esse ano", salienta Roberto Pontual. "E em nossa justificativa está explícito que, nos próximos salões, outras comissões, em função de seus momentos especificos, deverão apresentar outros projetos, mantendo o salão rigorosamente em dia com a arte".13

\section{Salão de Arte Contemporânea de Campinas: "Arte no Brasil" - Documento/Debate -12 artistas.}

Neste ano o SACC apresentou-se de maneira diferente. Durante três dias, 07, 08 e 09 de novembro de 1975, doze artistas convidados debateram com o público suas obras mostradas em quarenta slides. Os artistas convidados foram Mira Schendell, Rubem Valentim, Sérgio Camargo, João Câmara, Tomie Otake, Mário Bueno, Antonio Henrique Amaral, Franz Weissman, Amilcar de Castro, Humberto Espíndola, Nelson Leirner e Maria Leontina. Os debates foram coordenados pelos críticos de arte Aracy Amaral, Frederico Moraes e Aline Figueiredo.

Como o Salão anterior, este teve uma grande importância e uma enorme divulgação, visto que existem críticas em inúmeros jornais e periódicos e, ademais, ele não permaneceu em Campinas, viajando para o Rio de Janeiro $-\boldsymbol{X}$ $\boldsymbol{S A C C}$ no $\boldsymbol{M A M}$ (de 15 de janeiro a 8 de fevereiro de 1976) com debates nos

\footnotetext{
12 Veja, São Paulo, 30 de outubro de 1974, p.25.

${ }^{13}$ Idem, p.27.
} 
dias 17 e 18 de janeiro com os artistas e os críticos de arte, São Paulo $-\boldsymbol{X}$ SACC na Pinacoteca do Estado (de 16 a 30 de março de 1976), com debates nos dias 19, 20 e 21 de março e Brasília - X SACC em Brasília - Fundação Cultural do Distrito Federal (de 04 a 16 de abril de 1976), com debates nos dias 14,15 e 16 de abril.

Esta mostra já passou por diversas modificações, na tentativa de ser atual, em termos de objetivos e métodos. Primeiro, em 1971, no VII SACC, a comissão julgadora do certame de então, reuniu-se após sua tarefa para debater os benefícios e malefícios da exposição, tal como ela ali se encontrava. Das soluções propostas, chegou-se finalmente, em 1974, a sua primeira tentativa mais radical de atualização, quando o júri do momento decidiu fazê-la girar em torno de um tema. E assim nasceu o IX Salão de Arte Contemporânea de Campinas Desenho Brasileiro 74, vista não apenas na cidade de origem, mas também no Rio de Janeiro e em Brasilia.

Assim, para a edição de 1975, o Salão abriu-se ainda mais radicalmente modificado. Se em 1974 houvera a intenção de equilibrar o sistema tradicional do concurso com a necessidade de contar com artistas significativos através do convite direto, no X SACC eliminou-se por completo o primeiro modo. A comissão julgadora voltou-se apenas para o princípio do convite, escolhendo doze artistas brasileiros "com obra em plena maturidade, obras que se caracterizassem pela atualidade no nosso contexto, uma abrangência em termos territoriais assim como a diversidade das tendências vigentes".

No entanto, o dado mais radical e importante deste Salão é que dele foi eliminada a presença direta, ou seja, física da obra. Ao invés de comparecer com duas ou três obras, cada artista encarregou-se de preparar uma documentação visual, em slides, capaz de indicar suas pretensões e os caminhos percorridos para pô-las em prática. Acompanhando a documentação visual, um texto depoimento, publicado em catalogo, transferiu ao público o conhecimento da maneira pela qual o artista encara sua própria evolução, no contexto que o caracteriza. Citando o crítico Roberto Pontual "não épreciso dižer mais nada para comprovar a oportunidade e a utilidade de uma exposição como esta, que se mostrou suficientemente capaz de ousadia, com vistas a manter um mínimo de substância justificadora". ${ }^{14}$

Renata Cristina de Oliveira Maia Zago. Aluna do último semestre do bacharelado em Educação Artística - Artes Plásticas - Unicamp. Iniciações científicas: SAE/Pibic - julho de 2002 a agosto de 2003 - ToulouseLautrec e as mulheres da noite e Fapesp - fevereiro a dezembro de 2004 - As obras do acervo do MACC nos Salões de Arte Contemporanea de Campinas: 1960 e 1970.

${ }^{14}$ Jornal do Brasil, Rio de Janeiro, 15 de janeiro de 1976. 